\title{
MALIGNANT TRANSFORMATION IN A MATURE CYSTIC TERATOMA OF THE OVARY: A CASE OF RARITY
}

Lekha M. B1, Vijaya C², Archana Shetty³, Jayalakshmi V. J4

\section{HOW TO CITE THIS ARTICLE:}

Lekha M. B, Vijaya C, Archana Shetty, Jayalakshmi V. J. "Malignant Transformation in a Mature Cystic Teratoma of the Ovary: A Case of Rarity". Journal of Evolution of Medical and Dental Sciences 2014; Vol. 3, Issue 16, April 21; Page: 4331-4335, DOI: 10.14260/jemds/2014/2439

\begin{abstract}
Germ cell tumors account for a majority of all ovarian tumors. Ninety five percent of germ cell tumors are dermoid cysts (Mature cystic teratoma). Carcinomas arising from mature cystic teratoma are quite rare. The most common malignancy being Squamous cell carcinoma (75\%). In the present study we report a case of Squamous cell carcinoma arising in a mature cystic teratoma. A 45 year old female presented with mass in abdomen, pain abdomen and dysuria since one month. Total abdominal hysterectomy with bilateral salpingo-opherectomy was done. Histopathology showed well differentiated invasive squamous cell carcinoma arising in the background of mature cystic teratoma (dermoid cyst). Purpose of this report was to create awareness among practitioners to consider this possibility in dermoid cysts of large size in older patients.
\end{abstract}

KEYWORDS: Mature cystic teratoma, malignant transformation, squamous cell carcinoma, ovarian malignancy.

INTRODUCTION: Mature cystic teratomas (MCT), composed of well differentiated tissues derived from the three germ cell layers (ectoderm, mesoderm and endoderm) is the most common tumor of the ovary and accounts for $10-20 \%$ of all ovarian tumors in women of reproductive age. ${ }^{1}$ Malignant transformation in a MCT of the ovary is rare, with an incidence of less than $3 \% .{ }^{2}$ Preoperative diagnosis of malignant transformation in an ovarian cystic teratoma is often difficult due to nonspecific tumor markers and imaging findings. In the present report, we describe a case of squamous cell carcinoma (SCC) arising in a MCT. Although tumor markers may be raised in patients with squamous cell carcinoma arising from MCT, it is difficult to use tumor markers to distinguish between MCT\& SCC arising from an MCT as tumor markers can also be elevated in MCT. ${ }^{3}$ Hence this rare type of malignant transformation should be kept in mind when faced with a dermoid cyst, especially in older patients or patients with larger than unusual cysts.

CASE REPORT: A 45 year old female presented to the gynecological outpatient department with mass in the abdomen since a month, lower abdominal pain since 15 days and dysuria. Clinical examination showed a palpable lump in the right iliac fossa of 14 weeks size arising from the pelvic cavity. No free fluid was detected in pelvic cavity. Ultrasonography of the abdomen and pelvis showed a right adnexal mass measuring $10 \times 6 \mathrm{~cm}$, hyperechoic with calcification, having partly solid and cystic areas which was suspicious of malignancy. Laboratory studies revealed microcytic anemia with a hemoglobin level of $10 \mathrm{~g} / \mathrm{dl}$. CA-125 level was $82.50 \mathrm{u} / \mathrm{ml}$.

Pap smears were negative for malignancy. Hysterectomy with bilateral salpingo-ophorectomy was done and the excised specimen sent for histopathological examination. Uterus with cervix measured $7.5 \times 4.5 \times 2.5 \mathrm{cms}$. Right ovary showed a cystic mass measuring10x10x8cms.Outer surface of the tubo -ovarian mass was smooth and grey white. Cut section showed a multilocular cyst exuding 
pultaceous material, hair with a solid grey white area measuring $2.5 \mathrm{~cm}$ in diameter. [Fig. 1] Microscopic examination from the cyst wall showed mature squamous epithelium [Fig. 2]. with the solid area showing islands of carcinoma cells having clear to eosinophilic cytoplasm, vesicular nuclei, mild to moderate pleomorphism, infiltrating the ovarian stroma [Fig. 3]. In addition central whorling, individual cell keratinisation, with keratin pearls was seen [Fig. 4]. Mitotic figures were frequent and focal intracellular and extracellular keratin was present (squamoid differentiation) with dense inflammation and extensive necrosis. Cervix showed features of chronic cervicitis and no other sites were found to be having any evidence of SCC. A final diagnosis of Well Differentiated Squamous cell carcinoma arising in a Dermoid cyst of the ovary was made. Post- operative course was uneventful after which the patient was referred to the oncology department, for combination chemotherapy.

DISCUSSION: Ovarian germ cell tumors account for around $20-30 \%$ of ovarian neoplasms and 5\% of ovarian malignancies. ${ }^{3}$ Mature cystic teratoma (MCT) is the most common ovarian germ cell tumor (10-20\%) of all ovarian tumors. Teratomas include tissues originating from the three different germ cell layers and all of those tissues have the potential to undergo malignant transformation. Malignant transformation of MCT is an uncommon complication .The most common malignancy arising in dermoid cysts is squamous cell carcinoma (SCC), which represents about $75 \%$ of the cases of malignant transformation, followed by adenocarcinoma, sarcoma, carcinoid, thyroid carcinoma and melanoma. ${ }^{4}$

As SCC arising in MCT is quite rare, one must exclude metastasis, particularly from the cervix. Stromal invasion by malignant appearing squamoid epithelium should be used as the diagnostic criteria for categorizing MCT with malignant transformation.

Preoperative diagnosis of an MCT of the ovary is relatively easy due to the radiological detection of bony tissues which includes teeth, bones and cartilages. However, preoperative diagnosis of malignant transformation is very difficult clinically, because this tumor cannot be readily differentiated from an uncomplicated MCT or other ovarian tumour. ${ }^{1}$ SCC in a mature cystic teratoma commonly occurs in women over the age of 40years.The frequency of malignant change increases with increase in age rising to $19 \%$ in women after menopause. In most series, the median age at diagnosis of malignant transformation was 54-61 years. ${ }^{5}$ In the case reported above the patient age was 45 years, which is relatively younger.

Most common symptoms of this entity are abdominal pain, palpable mass and abdominal distention. However some patients remain asymptomatic at diagnosis. ${ }^{6}$ SCC arising in mature cystic teratomas often present as an incidental pathologic finding. In our case, the patient presented with pain abdomen and dysuria. MCT with diameter $>10 \mathrm{cms}$ is associated with increased risk of malignancy. ${ }^{7}$ In our case the tumor size was $10 \mathrm{~cm}$. Chiang et al stated that higher concentration of serum CA-125 levels are associated with survival rates. In our case CA-125 level showed elevation. In addition SCC antigen may be a useful marker to detect this disease preoperatively. ${ }^{8}$

The malignant component of MCT sometimes exists in only a part of the lesion, causing difficulty in its identification grossly. A tumor arising in MCT may appear grossly as polypoidal mass, mural nodule or mural plaques or area of hemorrhage and necrosis. ${ }^{9}$ So every case of MCT should be carefully grossed. The malignant component in our case presented as solid nodule. SCC arising in MCT can be seen microscopically as nests of squamous cells infiltrating the stroma as well as cysts lined by malignant squamous cells as seen in the case presented. Other histological patterns are 
papillary, insular, verruciform as well as spindle cell type. In high grade tumors, squamous differentiation is inconspicuous. ${ }^{8}$

Pathologic factors, grade and mode of infiltration can provide valuable information for predicting the survival of patients with squamous cell carcinoma arising from mature cystic teratoma. When malignant transformation has occurred within a teratoma, treatment is usually tailored towards the transformed histology. ${ }^{3}$ Optimal approach to the management of patients with advanced stage and recurrent disease is unclear.

Post treatment in the literature included single agent or combination chemotherapy, radiotherapy or a combination of these modalities. Results of these treatment regimens were variable and have not been systemically evaluated in adequate number. ${ }^{5}$ Therefore the optimal adjuvant therapy for SCC arising from an MCT has not been established.

CONCLUSION: Although mature cystic teratomas are a common category of ovarian tumors, malignant transformation in them is rare and often presents as incidental findings. We present this case to highlight the importance of keeping in mind this possibility, when operating surgeons come across large dermoid cysts in clinical practice.

\section{REFERENCES:}

1. Kurman R J. Blaustein's Pathology of the Female Genital Tract.5th edition NewYork : Springer Verlag;2002

2. Curling $\mathrm{ON}$, Potsides $\mathrm{PN}$, Hudson $\mathrm{CN}$. Malignant change in benign cystic teratoma of the ovary.Br J Obstet Gynaecol.1979; 86: 399-402.

3. Hackethal A, Brueggmann D, Bohlmann MK, Franke FE, Tinneberg HR, Münstedt K. Squamouscell carcinoma in mature cystic teratoma of the ovary: systematic review and analysis of published data. Lancet Oncol 2008; 9:1173-80.

4. Maslin P, Luchs JS, Haas J, Katz DS. Ovarian teratoma with malignant transformation: CT diagnosis. Am J Roentgenol 2002; 178: 1574

5. Dos Santos L, Mok E, Iasonos A, Park K, Soslow RA, Aghajanian C et al. Squamous cell carcinoma arising in mature cystic teratoma of the ovary: A case series and review of the literature. Gynecol Oncol.2007; 105:321-324.

6. Tseng CJ, Chou HH, Huang KG, Chang TC, Liang CC, Lai CH, et al. Squamous cell carcinoma arising in mature cystic teratoma of the ovary. Gynecol Oncol.1996 63:364-370

7. Yamanaka Y, Tateiwa Y, Miyamoto H, Umemoto Y, Takeuchi Y, Katayama K, et al Preoperative diagnosis of malignant transformation in mature cystic teratoma of the Ovary. Eur J Gynaecol Oncol 2005; 26: 391-2.

8. A.J Chiang, V .La, J. Peng, K. J. Yu, and N.N.H .Temg. Squamous cell carcinoma from arising mature cystic teratoma of the ovary. International Journal of Gynaecological Cancer, vol.21, no.3, pp.466-474, 2011.

9. Stern JL, Buscema J, Rosenshein NB, Woodruff JD. Spontaneous rupture of benign cystic teratomas. Obstet Gynecol. 1981; 57: 363-6. 


\section{CASE REPORT}

Fig. 1: Gross hysterectomy specimen with attached Dermoid ovarian cyst showing solid grey white area with tooth and hair.

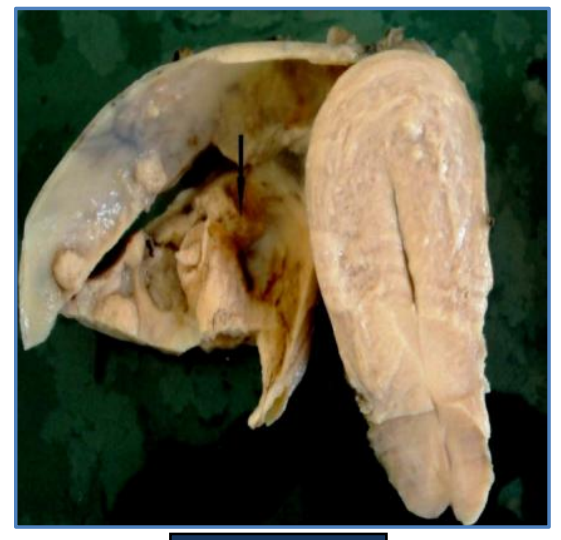

Figure 1

Fig. 2: Hand E stain 10X showing cyst wall lined by mature stratified squamous epithelium.

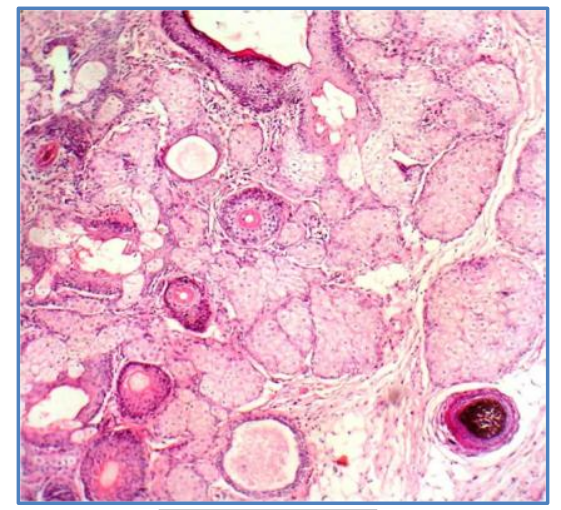

Figure 2

Fig. 3: $\mathrm{H}$ and $\mathrm{E}$ stain $10 \mathrm{X}$ showing infiltrating islands of tumor cells surrounded by sparse inflammatory cells.

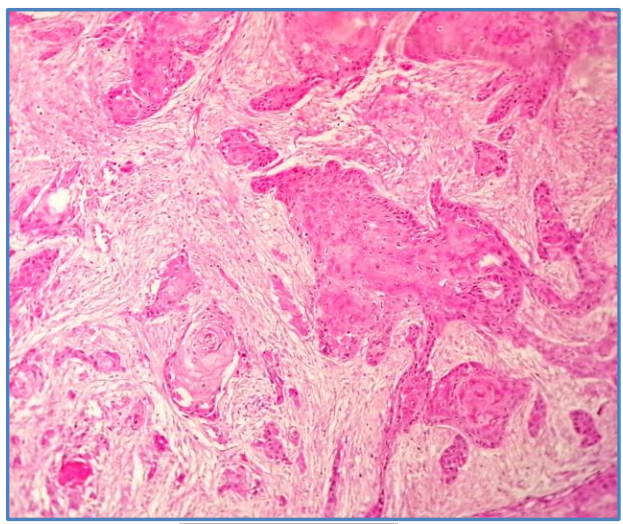

Figure 3 


\section{CASE REPORT}

Fig. 4: Hand E stain 10X showing squamous cell carcinoma with multiple keratin pearls.

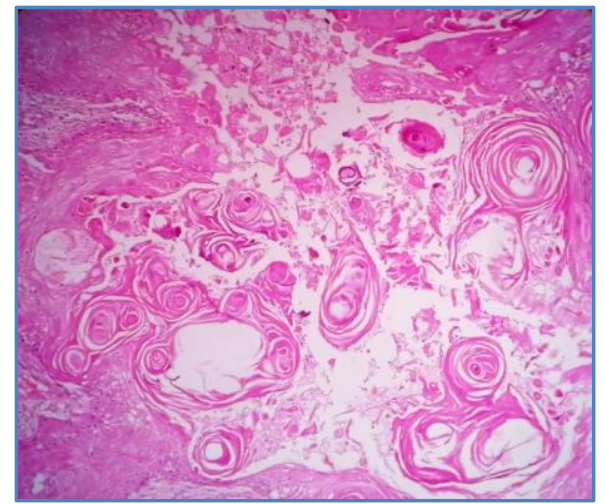

Figure 4

\section{AUTHORS:}

1. Lekha M. B.

2. Vijaya $\mathrm{C}$

3. Archana Shetty

4. Jayalakshmi V. J.

\section{PARTICULARS OF CONTRIBUTORS:}

1. Assistant Professor, Department of Pathology, Sapthagiri Institute of Medical Sciences and Research Center, Bangalore.

2. Professor and HOD, Department of Pathology, Sapthagiri Institute of Medical Sciences and Research Center, Bangalore.

3. Assistant Professor, Department of Pathology, Sapthagiri Institute of Medical Sciences and Research Center, Bangalore.
4. Tutor, department of Pathology, Sapthagiri Institute of Medical Sciences and Research Center, Banglaore.

\section{NAME ADDRESS EMAIL ID OF THE CORRESPONDING AUTHOR:}

Dr. Lekha M. B, Department of Pathology, Sapthagiri Institute of Medical Sciences and Research Center, Street No. 15, Hesaraghatta Main Road, Chikkasandra, Bangalore - 560090 .

E-mail:dr_lekha@rediffmail.com

Date of Submission: 20/03/2014. Date of Peer Review: 21/03/2014. Date of Acceptance: 03/04/2014. Date of Publishing: 21/04/2014. 